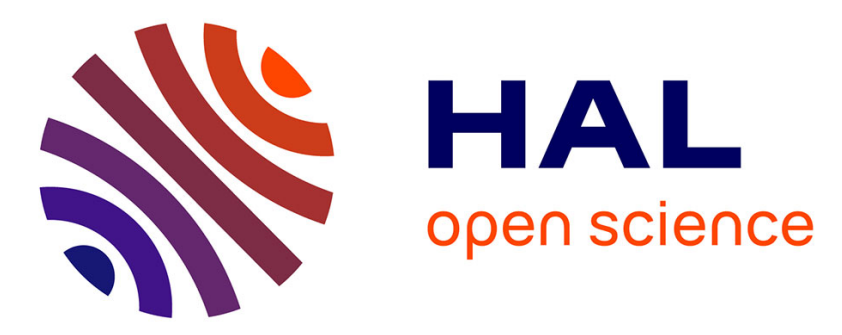

\title{
The core component of the mammalian SWI/SNF complex SMARCD3/BAF60c is a coactivator for the nuclear retinoic acid receptor
}

Sébastien Flajollet, Bruno Lefebvre, Céline Cudejko, Bart Staels, Philippe Lefebvre

\section{To cite this version:}

Sébastien Flajollet, Bruno Lefebvre, Céline Cudejko, Bart Staels, Philippe Lefebvre. The core component of the mammalian SWI/SNF complex SMARCD3/BAF60c is a coactivator for the nuclear retinoic acid receptor. Molecular and Cellular Endocrinology, 2007, 270 (1-2), pp.23. 10.1016/j.mce.2007.02.004 . hal-00531916

\section{HAL Id: hal-00531916 https://hal.science/hal-00531916}

Submitted on 4 Nov 2010

HAL is a multi-disciplinary open access archive for the deposit and dissemination of scientific research documents, whether they are published or not. The documents may come from teaching and research institutions in France or abroad, or from public or private research centers.
L'archive ouverte pluridisciplinaire HAL, est destinée au dépôt et à la diffusion de documents scientifiques de niveau recherche, publiés ou non, émanant des établissements d'enseignement et de recherche français ou étrangers, des laboratoires publics ou privés. 


\section{Accepted Manuscript}

Title: The core component of the mammalian SWI/SNF complex SMARCD3/BAF60c is a coactivator for the nuclear retinoic acid receptor

Authors: Sébastien Flajollet, Bruno Lefebvre, Céline Cudejko, Bart Staels, Philippe Lefebvre

PII: S0303-7207(07)00077-9

DOI: doi:10.1016/j.mce.2007.02.004

Reference: MCE 6621

To appear in: $\quad$ Molecular and Cellular Endocrinology

Received date: $\quad$ 19-10-2006

Revised date: $\quad 10-1-2007$

Accepted date: $\quad$ 5-2-2007

Please cite this article as: Flajollet, S., Lefebvre, B., Cudejko, C., Staels, B., Lefebvre, P., The core component of the mammalian SWI/SNF complex SMARCD3/BAF60c is a coactivator for the nuclear retinoic acid receptor, Molecular and Cellular Endocrinology (2007), doi:10.1016/j.mce.2007.02.004

This is a PDF file of an unedited manuscript that has been accepted for publication. As a service to our customers we are providing this early version of the manuscript. The manuscript will undergo copyediting, typesetting, and review of the resulting proof before it is published in its final form. Please note that during the production process errors may be discovered which could affect the content, and all legal disclaimers that apply to the journal pertain. 


\title{
The core component of the mammalian SWI/SNF complex SMARCD3/BAF60C is a coactivator for the nuclear retinoic acid receptor
}

\author{
Sébastien Flajollet ${ }^{1,2,3}$, Bruno Lefebvre ${ }^{1,2,3}$, Céline Cudejko ${ }^{1,2,3}$, Bart Staels ${ }^{1,2,3}$ and Philippe Lefebvre ${ }^{1,2,3,4}$ \\ ${ }^{1}$ Institut Pasteur de Lille, Département d'Athérosclérose, Lille, F-59019, France; \\ ${ }^{2}$ Inserm, U545, Lille, F-59019 France; ${ }^{3}$ Université de Lille 2, Lille, F-59006 France.
}

Running title: RAR-mediated transcription and SWI/SNF complexes

Keywords: transcription, chromatin, nuclear receptors, coactivator

\footnotetext{
${ }^{4}$ Corresponding author: Tel. +33.3.20.62.68.76, Fax. +33.3.20.62.68.87, email: p.lefebvre@lille.inserm.fr
} 


\begin{abstract}
Retinoic acid receptors (RARs) activate transcription by recruiting coactivator complexes such as histone acetyltransferases (HAT) and the Mediator complex, to increase chromatin accessibility by general transcription factors and to promote transcription initiation. Indirect evidences have suggested a role for the ATP-dependent chromatin remodeling complex SWI/SNF in RAR-mediated transcription. Here we demonstrate that two highly related subunits of the core SWI/SNF complex, BAF60c1 and BAF60c2, interact physically with retinoid receptors and are coactivators for RARs. This coactivating property is dependent on SRC1 expression, showing that HATS and SWI/SNF cooperate in this retinoid-controlled transcriptional process.
\end{abstract}




\section{INTRODUCTION}

A fundamental role of eukaryotic transcription factors is to overcome the physical barrier that chromatin organization imposes on the access of these transcriptional regulators to DNA. Evolution has designed two main strategies to modulate chromatin structure and to favor transcription factors binding to DNA. The first one relies on the covalent modification of amino-acids located in histone tails, such as acetylation, phosphorylation, methylation. These post-translational modifications, which target in most cases, but not exclusively, histone $\mathrm{H} 3$ and histone $\mathrm{H} 4$, modify the role played by nucleosomal DNA sequences. These covalent modifications impact on the affinity of histone tails for DNA, thereby increasing the physical accessibility of cis-acting sequences. Moreover, these post-translational modifications create novel docking sites on nucleosmes, allowing the tight binding of proteins to modified histones, thereby controlling the structure, function and dynamics of chromatin. Introducing non covalent modifications of chromatin structure is the second strategy used, which is based on the recruitment, to regulated promoters, of evolutionary conserved ATPase-containing complexes. Several ATPase-dependent remodelling complexes have been identified, such as the mating type switch/sucrose non fermenting (SWI/SNF), the imitation of switch (ISWI), the nucleosome remodeling and deacetylating (NuRD) and the chromatin accessibility (ChRAC) complexes. Their action leads to several structural modifications, ranging from the loss of nucleosome(s) to extraction of histone H2A and H2B (Eberharter and Becker, 2004).

The human SWI/SNF complexes organize around two ATPases, Brahma (hBRM) and brahma-related gene 1 (BRG1) (Kingston and Narlikar, 1999;Peterson, 2002). These ATPases possess a bromodomain, allowing their binding to acetylated histones. Several hBRM- or BRG1-containing complexes have been isolated (Mohrmann and Verrijzer, 2005), and a minimal complex made of hBRM or BRG1 [which are mutually exclusive and functionally distinct subunits (Bultman et al., 2000)], SNF5/INI1, the Brahma associated factors BAF155 and BAF170, is essential for efficient chromatin remodeling in-vitro (Phelan et al., 1999).

Several SWI/SNF complexes (BRM, BRG1, BAF or PBAF ), characterized by a distinct subunit composition, have been isolated from mammalian cells (Wang et al., 1996). The core component of the BRM, BRG1, BAF or PBAF complexes are an ATPase subunit, SNF5/INI1, BAF155, BAF170, BAF60, BAF53 and $\beta$-actin. Specific components of the PBAF complex are BAF180 and BAF200 (Yan et al., 2005), whereas BAF250 is found exclusively in the BAF complex (Roberts and Orkin, 2004). In addition, BAF60c is expressed in a cell-specific manner during development (Lickert et al., 2004), adding a layer of complexity to the structure, and very likely to the function of these multimeric complexes. While their roles in transcriptional regulation have been extensively characterized, other studies have pointed to their involvement in viral integration and expression, DNA synthesis and cell cycle control (Olave et al., 2002b;Wang, 2003;de la Serna et al., 2006). Importantly, signaling pathways regulate BAF complexes by post-translational modifications (Bourachot et al., 2003;Simone et al., 2004).

Retinoic acid receptors (RARs and RXRs) are ligand-regulated transcription factors belonging to 
the nuclear receptor (NR) superfamily, which comprises 48 members in the human genome. NRs can be regulated by endocrine signals such as steroids or dietary cues such as fatty acids which behave as ligands for these NRs, while a subset of this family (orphan receptors) is regulated in a ligand-independent manner. RARs activate transcription upon agonist binding, which induces the sequential dismissal of corepressor complexes and the recruitment of coactivator complexes (Lefebvre et al., 2005). Several types of coactivator complexes are known to be recruited to RARs upon agonist binding, and we recently demonstrated that SRC1, a member of the p160 family of coactivator, is critical for the regulation of two retinoid-regulated genes, RARß2 and CRABPII. In contrast, Med1/DRIP205/TRAP220, a component of the Mediator complex interacting directly with RAR, appeared to have a repressive role in this model (Flajollet et al., 2006).

The use of a RAR-dependent, in-vitro transcription system suggested that hSWI/SNF complexes are involved in late steps of the transcriptional activation of a retinoid-inducible, chromatinized template (Dilworth et al., 2000). Gene ablation of the polybromo protein BAF180 gene led to a partial decrease of the expression of RARß2 gene, whereas CRABPII expression was totally abrogated in this BAF180deficient background (Wang et al., 2004). Therefore transcriptional regulation by RARs seems to involve distinct coactivator complexes, including the hSWI/SNF and ISWI complexes, the Mediator complex, histone acetyl transferases (HATs such as CBP/p300, pCAF) and p160 proteins. The role of BAF180 in retinoid-mediated transcription suggested that PBAF is an important coactivator for RARs. However, the mild phenotype of BAF $180^{-/-}$mice suggests that not all retinoid-regulated genes require PBAF for optimal expression. PBAF regulates selectively vitamin D receptor (VDR)- and peroxisome proliferator activated receptor gamma (PPARY)-mediated transcription in-vitro, but not SP1 or SREBP1c-mediated transcription (Lemon et al., 2001).

The interaction between nuclear receptors and SWI/SNF complexes may occur through distinct subunits of the complex. The glucocorticoid receptor, whose ability to activate several target genes is dependent on BRG-1 expression, interacts physically with BRG-1, BAF57 and BAF60c (Fryer and Archer, 1998; Hsiao et al., 2003;Trotter and Archer, 2004). The estrogen receptor is able to engage interactions with BRG-1, BAF57 and BAF250 (Ichinose et al., 1997;Belandia et al., 2002), whereas BAF60c is a promiscuous partner for several nuclear receptors, including PPARY, RXR $\alpha, F X R \alpha, S F 1$ and ROR $\alpha 1$ (Debril et al., 2004). Other interactions have also been demonstrated, including Brm/SHP, BAF57/androgen receptor, BAF60a/progesterone receptor, BAF60a/FXR (Hsiao et al., 2003;Kemper et al., 2004;Link et al., 2005). SWI/SNF complexes act in most instance as coactivators for nuclear receptors, including PPARY (Salma et al., 2004), although they may exert a repressive activity toward various transcription factors (Murphy et al., 1999) through their association with corepressors (Underhill et al., 2000;Sif et al., 2001 ;Deckert and Struhl, 2002;Battaglioli et al., 2002), including nuclear receptors (Kemper et al., 2004).

As part of an effort to characterize more precisely the nature and the functions of coactivators and corepressors of RARs (Martin et al., 2003;Martin et al., 2005;Lefebvre et al., 2006;Flajollet et al., 2006), 
we undertook a study aiming at characterizing the role of SWI/SNF complexes in RAR-mediated transcription. We demonstrate here that BAF60c proteins exert RAR-coactivating properties essentially through a direct interaction with the RAR coactivator binding interface. In addition, BAF60c coactivating property is dependent on SRC1 expression, although neither BAF60c1 or BAF60c2 are able to engage direct interaction with this $\mathrm{p} 160$ protein. 


\section{MATERIALS AND METHODS}

\section{Reagents}

atRA was obtained from Sigma. DNA restriction and modification enzymes were purchased from Promega.

\section{Plasmids}

The plasmids encoding for BAF60c1 and BAF60c2 (pSG5- and pGST-) were a gift from J. Auwerx (IGBMC, Illkirch, France), The pGST-BAF57 expression vector was a gift from B. Belandia (I.C.L., U.K.) whereas pGST-BAF250 and pCIneo-BAF250 were from Z. Nie (N.I.H., U.S.A.). GST fusion proteins encoded for the full length version of BAF57, BAF60c1 and BAF60c2, whereas the 382-842 fragment of SRC1 and the 1670-2171 fragment of BAF250 were fused to GST. p(GRARE)3tkLuc, pSG5-RXGR, pSG5-hRAR $\alpha$, pSG5-RAR $\alpha \Delta A B, p S G 5-R A R \alpha \Delta E / F, p S G 5-R A R \alpha-K 244, p S G 5-R A R \alpha-K 244,262 A$ and pSHAG-SRC1 were described in (Lefebvre et al., 1998a;Mouchon et al., 1999;Flajollet et al., 2006). The $\mathrm{ERE}_{3}$-tk Luc

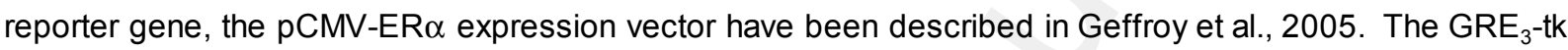
Luc and the pRSV-rGR constructs are described in Prima et al., 2000. The pSilencerBAF60c encoding for a anti-BAF60c1\&2 small hairpin RNA was synthetized and cloned following a strategy described elsewhere (Flajollet et al., 2006). The selected anti-BAF60c siRNA was: cagatgggttccaagtgaag.

\section{GST-pulldown assays}

Glutathione S-transferase (GST)-fusion proteins expressed in BL21/DE3-pLysS bacteria were adsorbed on glutathione-Sepharose 4B beads as previously described (Lefebvre et al., 1998b). ${ }^{35}$ S-labeled proteins $\left({ }^{35} S\right]$ methionine was from GE Healthcare) were synthesized using the in-vitro coupled transcription/translation kit from Promega (T7 TNT Quick Rabbit Reticulocyte kit). $3 \mu \mathrm{L}$ of each reaction were diluted in $150 \mu \mathrm{L}$ of GST binding buffer $(20 \mathrm{mM}$ Tris- $\mathrm{HCl}, \mathrm{pH} 7.8,100 \mathrm{mM} \mathrm{KCl}, 0.05 \% \mathrm{NP} 40,1 \mathrm{mM}$ DTT, $20 \%$ glycerol) and pre-incubated in the absence or the presence of ligand for 1 hour at room temperature with gentle rotation. Extracts were then incubated for 1 hour at room temperature with an equal amount of fusion protein bound to GST-Sepharose, as verified by Coomassie Blue staining. Unbound material was removed by three successive washes $(20 \mathrm{mM}$ Tris- $\mathrm{HCl}, \mathrm{pH} 7.4,100 \mathrm{mM} \mathrm{KCl}, 0.1 \% \mathrm{NP} 40,1$ mM DTT, $20 \%$ glycerol). Resin-bound proteins were eluted in PAGE-SDS loading buffer and separated by $10 \%$ sodium dodecyl sulfate-polyacrylamide gel electrophoresis. Labeled proteins were visualized with a Molecular Dynamics Storm 860 phosphorimager (Molecular Dynamics). At least three independent experiments were carried out with different bacterial extracts for each experiment.

\section{HeLa and P19 culture and transfection}

P19 EC and HeLa Tet-On cells were maintained at $37{ }^{\circ} \mathrm{C}, 5 \% \mathrm{CO}_{2}$ in Dulbecco's modified Eagle medium (DMEM) supplemented with 10\% fetal calf serum (Biowhittaker), 1,000 U penicillin and $10 \mu \mathrm{g}$ streptomycin 
per $\mathrm{mL}$. One day prior to transfection, cells were plated in 6-wells plates. Each well was transfected using Lipofectamine2000 (Invitrogen) according to the manufacturer's instructions, with a DNA mixture including $1 \mu \mathrm{g}$ of the DR5-driven, RA-responsive firefly luciferase reporter gene [GRARE3-tk luc, (Depoix et al., 2001) referred to as DR5-tk Luc in the manuscript], $50 \mathrm{ng}$ of a control plasmid tk-renilla luciferase (Promega) and various amounts of other plasmids as indicated in each legend. The total amount of transfected DNA was adjusted to $4 \mu \mathrm{g}$ per well. When indicated, the RAR expression vector was substituted for a ER expression vector (Geffroy et al., 2005) or a GR expression vector (Prima et al., 2000) and the adequate reporter gene. Twenty four hours after transfection, cells were challenged overnight with $1 \mu \mathrm{M}$ atRA. Cells were harvested and luciferase activities were assayed with the Dual-Glo Luciferase Assay System (Promega). Firefly luciferase values were normalized to those of renilla.

\section{Cellular extracts preparation, coimmunoprecipitation assays and Western Blot analysis}

Cellular extract preparation and western blot analysis were carried out as previously described (Lefebvre et al., 2002a). For coimmunoprecipitation experiments, cells were treated for 2 hours with $1 \mu \mathrm{M}$ atRA or left untreated and lysed as described previously (Martin et al., 2005). Immunodetections were performed using the following antibodies: monoclonal anti-actin antibody (ac-15, Sigma), monoclonal anti-SMARCD3 antibody (M01, Abnova Corp.), polyclonal anti-BRG1, anti-BAF250, anti-SRC1 and anti-RAR $\alpha$ (sc-17796, sc-32761, M-341 and sc-551 respectively, Santa Cruz Biotech.).

\section{Immunofluorescence and GFP detection.}

The experimental procedure is as in Prima et al., 2000.

\section{RNA preparation, Reverse Transcription-PCR, and quantitative PCR oligonucleotides.}

Total RNA purification and RT-PCRs were carried out as described (Brand et al., 2002). Amplification conditions were adjusted to be within linear range. Sequences of primers used for PCR were : $\beta$-actin: 5 '-atcatgtttgagaccttcaa-3' and 5'-catctcttgctcgaagtcca-3'; mSMARCD3 (209-866) 5'-gcgcgcaaagccacgaaaa-3' and 5'-tccggtgccactcaacaagg-3', BAF60c2 5'-gcgcgcaaagccacgaaaa-3' and 5'-tccggtgccactcaacaagg-3', SRC1: 5'-aatgtgttcagtcaagctgtccag-3' and 5'-tggttattcagtcagtagctgctg-3'.

\section{Quantitative PCR}

Mouse RARß2 transcripts were detected and analyzed as described in (Flajollet et al., 2006).

\section{Chromatin immunoprecipitation assays}

ChiP assays were performed as described in (Lefebvre et al., 2002b;Flajollet et al., 2006) using anti-RAR C-20) and anti-SRC1 (M-341) antibodies. Briefly, formaldehyde-crosslinked chromatin was sonicated and immuno-precipitated with either a non-specific IgG or the indicated antibody. ChIP analysis were performed at least in triplicate using distinct DNA preparations. Immuno-precipitated DNA was purified and quantified, 
after a first characterization by regular PCR (32 cycles), by Q-PCR using an ABI PRISM 7700 sequence detection system. The RAR 32 promoter sequence was in this case amplified from -78 to +38 with the following primers: Forward: ttgaaggttagcagcccgg, Reverse: cttctgtcacacggaatgaaagat, probe FAM/TAMRA: aaggttcaccgaaagttcactcgca. The exon 3 sequence was amplified using the following primers: 5'-tcagtggattcacccaggc-3' and 5'-tcgggacgagctcctcag-3' with the FAM/TAMRA probe 5'cagcaccggcatactgctcaa-3'. DNA was quantified and results expressed relative to input DNA, after substracting non-specifically bound DNA as assayed using a nonspecific IgG in the ChIP assay. Assays were run in triplicate. 


\section{RESULTS}

\section{BAF60c1 and BAF60c2 exert coactivating properties on RAR-mediated transcription.}

Several components of SWI/SNF complexes have been shown to contain the LXXLL nuclear receptor interaction motif (Mohrmann et al., 2005), such as BAF250, BAF60c and BAF170. The ability of BAF57, BAF250 and BAF60c proteins to potentiate retinoid-induced transcription was first assessed in a transient transfection assay in HeLa cells, and compared to that of p160 proteins (SRC1, 2 and 3, Figure $1 A$ ). In our system, transactivation is mediated solely through RAR, since RXR is non permissive in this setting. SRC1 and SRC2 potentiated strongly the ligand-dependent activation of a DR5 RARE-driven reporter gene in this cellular background (4-fold), whereas SRC3 (pCIP/AIB1) was not active in our system. Overexpressing BAF57 and BAF250 did not modify significantly basal and retinoid-induced activities of the reporter gene. In contrast, both BAF60c1 and BAF60c2 displayed clearly detectable RAR-coactivating properties, and increased the retinoic acid (RA)-induced activity by 2 -fold. As control experiments, we also assessed the coactivating properties of SRC1, BAF57, BAF250 and BAF60c2 on ER $\alpha$ and GR transcriptional activity in strictly similar conditions (Figure 1B and 1C). In contrast to RAR $\alpha$, both ER $\alpha$ and GR transcriptional activities were sensitive to BAF57 and BAF250 overexpression, but BAF60c2 was inactive in these assays, as previously published (Belandia et al., 2002; Nie et al., 2000)..

We thus tested BAF60c1\&2 function in P19 cells, a RA-sensitive embryonal carcinoma cell line which is a cellular model suitable to study both transcriptional and differentiation processes initiated by retinoids (Lefebvre et al., 2002a;Flajollet et al., 2006). BAF60c1\&2 expression was therefore either knocked down using a small interfering RNA or increased upon transfection of a BAF60c2 expression vector in this cell line (Figure 1B, upper panel). Monitoring the expression by quantitative PCR of the endogenous RARß2 gene, which is also regulated through a DR5 RARE (de Thé et al., 1990), showed that overexpression of BAF60c2 exerted a mild potentiation on RA-induced RARB2 mRNA accumulation, suggesting that the level of expression of endogenous BAF60c2 in P19 cells is not as rate-limiting as it is in HeLa cells. However, knocking down BAF60c1\&2 expression had a strong impact on the activity of the RARß2 gene which became noticeable after 1 hour of RA treatment (Figure 1B, lower panel). After a 3 hours treatment, the observed inhibition reached more than $60 \%$ compared to wild type P19 cells, and was still of about $40 \%$ after a 16 hours challenge. Taken together, our data suggest that BAF60c proteins are potential coactivators for RAR $\alpha$ in two distinct cellular backgrounds.

\section{The BAF complex interacts with RAR $\alpha$ in intact cells.}

Our results showed a functional interaction in intact cells between BAF60c proteins and RXR/RAR heterodimers, bound either to plasmid DNA (transiently transfected reporter gene) or to a fully chromatinized DNA template (RARß2 promoter). Coimmunoprecipitations were thus carried out using P19 cellular extracts to investigate the physical interaction between endogenous RAR $\alpha$ and these SWI/SNF complex subunits (Figure 2A). Immunoprecipitating endogenous RAR $\alpha$ allowed the detection of BAF60c1\&2, which were 
interacting constitutively and in a ligand-insensitive manner with RAR $\alpha$. BAF250 displayed a similar pattern of interaction to that of BAF60c. Immunofluorescence studies showed that BAF60c was localized in both the cytoplasmic and nuclear compartment, whereas an overexpressed EGFP-tagged hRAR $\alpha$ was exclusively detected in the nucleus (Figure 2B).

To further investigate the pattern of interaction of BAF60c subunits with the promoter-associated RAR $\alpha$, we carried out chromatin immunoprecipitation assays on the RARß2 promoter (Figure 2C). In agreement with our previous results (Lefebvre et al., 2002b;Flajollet et al., 2006), both RAR $\alpha$ and SRC1 were constitutively bound to the promoter in a ligand-insensitive manner. As expected from coimmunoprecipitation assays, BAF60c proteins were tethered to the promoter in a ligand-insensitive manner. In contrast, BAF60c proteins could not be detected at exon 3 of the RARß2 gene (Figure 2D), whereas RNA polymerase 2 density increased at this locus in a ligand-dependent manner, as previously reported (Flajollet et al., 2006). Thus immunoprecipitation assays suggest that, despite having both LXXLL motifs, BAF250 and BAF60c proteins interact with RAR $\alpha$ in a ligand-independent manner, much like SRC1. Whether this applies to both $\mathrm{BAF} 60 \mathrm{c} 1$ and $\mathrm{BAF} 60 \mathrm{c} 2$ cannot be determined at this point, since immunoprecipitations were carried out with an antibody recognizing both isoforms.

\section{p160 coactivators act in synergy with BAF60c proteins on a retinoid-regulated promoter.}

Results described above suggest that distinct components of the SWI/SNF complex may engage interactions with promoter-bound RAR/RXR heterodimers. Since SRC1 and BAF60c1\&2 bound to the RARB2 promoter with a similar pattern, we tested whether $\mathrm{p} 160$ and BAF60c proteins could interact functionally (Figure 3). Hela cells were transfected with the DR5-tk Luc reporter gene, and RAR $\alpha$ and RXR $\alpha$ overexpression conferred RA sensibility to this system (Figure 3A). Overexpression of either SRC1 or SRC2 increased both the basal and the RA-induced luciferase activity, whereas SRC3 and p300 were inactive (Figure $3 \mathrm{~A}$ ). As shown above, BAF60c2 displayed coactivating properties in this system, and interestingly, co-expression of either SRC1 or SRC2 with BAF60c2 yielded an additive response. A identical result was obtained upon overexpression of BAF60c1 (data not shown). The additive effect between BAF60c1 or BAF60c2 with SRC1 was clearly dose-dependent, as shown in Figure 3B.

HeLa cells were then transiently transfected with a plasmid encoding for a shRNA directed against SRC1 mRNA (pSHAG-SRC1, Figure 3C). In agreement with a ca. $60 \%$ transfection efficiency, SRC1 expression was decreased by $40-50 \%$ when assayed by western blot analysis of whole cell extracts (insert, Figure 3C). In SRC1-depleted cells, overexpression of BAF60c2, together with RAR $\alpha$ and RXR $\alpha$ did not enhance significantly the transcriptional response of the reporter gene to atRA, in contrast to control cells (Figure $3 \mathrm{C}$ ). From this, we conclude that the BAF60c coactivating property is exerted through a SRC1dependent mechanism.

\section{BAF57 and BAF250, but not BAF60c1\&2, interact directly with SRC1.}

The functional potentiation and the detected physical interactions suggested that BAF60c proteins 
could interact physically with SRC1. We therefore tested this hypothesis using a GST pulldown approach, in which BAF proteins were fused to GST and used as a bait for labeled SRC1 (Figure 4). BAF250 and BAF57 interacted with SRC1 (Figure 4A). In sharp contrast, BAF60c proteins were unable to interact with $S R C 1$, suggesting that BAF60C interaction with the RAR $\alpha$-containing complex might take place through RAR $\alpha$ itself, or at least in a SRC1-independent manner. This hypothesis was further tested in the P19 cell background, in which a permanent depletion in SRC1 was induced upon stable transfection of a shRNAencoding vector targeting SRC1 mRNA [Figure 4B and (Flajollet et al., 2006)]. ChIP assays in control cells confirmed the ligand-insensitive and constitutive interaction of SRC1 and BAF60c1\&2 with the RARß2 promoter (Figure 4C). Knockdown of SRC1 expression resulted in a decreased association of this protein to the promoter. However, this depletion had no significant impact on BAF60c1\&2 binding to the promoter, confirming that SRC1 and BAF60c1\&2 do not interact physically with each other. These observations led us to speculate whether BAF60c polypeptides could interact directly with RAR $\alpha$.

\section{Only BAF60c2 interacts with RARs in a AF2-dependent manner.}

GST pulldown experiments were thus performed to assess the RAR-binding properties of BAF subunits (Figure 5). ER $\alpha$ was first used as a prototypical interactant with SRC1, BAF60c1\&2, BAF250 and BAF57. ER $\alpha$ turned out to interact in a strictly ligand-dependent manner with SRC1, BAF250 and BAF57. The interaction of $E R \propto$ with $B A F 60 c$ proteins was also ligand-dependent, but a significant basal interaction was detected (Figure 5A). RAR $\alpha, R A R \beta$, and RARY interacted with SRC1 in a ligand-dependent manner, and BAF250 exhibited a ligand-independent interaction with all three isotypes. Thus BAF250 may interact with RAR itself, in addition to SRC1 (Figure 4). We noted however that RARY interacted quite weakly with BAF proteins when compared to the $\alpha$ and $\beta$ isotypes. Similarly, the interaction of BAF60c1 with RARs was constitutive and not influenced by RA, whereas BAF60c2 interacted constitutively with the three isotypes and atRA increased moderately this interaction with RAR $\alpha$ and RARY. Finally, BAF57 displayed a significant affinity only for RAR $\beta$, opening the possibility that BAF57 could play a specific role in RAR 3 mediated transcription. We also investigated whether BAF proteins interact with the RAR dimerization partner RXR $\alpha$ in a similar assay. Quite strikingly, only BAF60c proteins could engage detectable interaction with $R X R$, and again, only BAF60c2 exhibited both a basal and ligand-induced interaction with RXR (Figure $5 A)$.

We thus sought to identify the molecular structure(s) allowing the interaction between BAF60c1 or BAF60c2 and RAR $\alpha$, using mutants of RAR $\alpha$ in a GST pull down assay (Figure $5 B$ and $5 C$ ). The isolated RAR $\alpha$ LBD was sufficient to mediate the basal and ligand-dependent RAR $\alpha-B A F 60 c 2$ interaction (Figure $5 B$ ), and both the $A / B$ and $C$ domains were dispensable for this interaction, although we noted that deletion of the $A$ and $B$ domains altered moderately the affinity of BAF60c1\&2 for RAR (Figure 5B and $5 C$ ). Point mutants in the LBD at K244 and K262 in the RAR $\alpha$ LBD prevent agonist-induced helix 12 folding, and thus inactivate the coactivator-RAR $\alpha$ binding interface and RAR $\alpha$ transcriptional activity [(Figure 5C) and (Mouchon et al., 1999)]. In GST-pulldown assays, mutations of K244 or of K244 and K262 were able to 
prevent the ligand-dependent recruitment of SRC1 to RAR $\alpha, B A F 60 c 1 \& 2$. In addition, the progressive alteration of the CoA binding interface (from hRAR $\alpha$ K244A to hRAR $\alpha$ K244,262A) decreased the basal interaction of both BAF60c1 and BAF60c2 with RAR $\alpha$. Similarly, deletion of a significant portion of the AF2 $A D$ region (hRAR $\alpha \Delta 376-408$ ) prevented the ligand-dependent interaction of RAR $\alpha$ with BAF60c2 and lowered the basal interaction with both isoforms. This indicates that the classical CoA binding interface is a very important structural determinant of BAF60c1\&2 interaction with RAR $\alpha$. However, an yet undetermined domain in the RAR $\alpha$ LBD is likely to contribute also to this ligand-independent interaction. 


\section{DISCUSSION}

Many studies have highlighted the function of the SWI/SNF complex in nuclear receptor-mediated transcriptional activation. Transcriptional coactivation of retinoic acid receptor by hSNF2 suggested a role of this complex in RAR-targeted chromatin remodeling (Chiba et al., 1994), and in-vitro transcription assays revealed a facilitating role of the PBAF complex in transcriptional activation by several NRs (Lemon et al., 2001). Gene ablation of the PBAF-specific subunit BAF180 impacted differentially the response of two RAtarget genes, RARB2 and CRABPII (Wang et al., 2004), underlining the role of the PBAF complex in RARmediated transcription. However, the association of BAF250 to RAR $\alpha$-containing complex (Figure 2A) suggest that BAF complexes may also play a functional role, at least in P19 cells. Finally, order of addition experiments in an in-vitro transcription assay showed that the SWI/SNF complex participates to the transcriptional activation of a DR5-regulated chromatin template at late stages of the transcriptional process (Dilworth et al., 2000). However, how the SWI/SNF complex exerts its coactivating function, from a molecular point of view, on RAR-mediated transcription is not clear at this time.

Here we show that the effect of the SWI-SNF complex on RA-induced transcription may involve its targeting to RA-regulated promoters, through a direct interaction of RXR/RAR heterodimers with BAF60c proteins. We could show that both BAF60c1 and BAF60c2 are coactivators of RAR in two distinct cellular backgrounds. BAF60c coactivation was dependent on SRC1 expression, however, no physical interaction could be detected between these two components. Since both proteins interact with RAR through its coactivator binding interface, and thus probably involving the LXXLL motif borne by BAF60c subunits, one may speculate that this functional synergy reflects a sequential recruitment of SRC1 then of the SWI/SNF complex to RA-regulated promoters, as suggested previously (Dilworth et al., 2000). This scenario would be in agreement with the observed delayed recruitment of the SWI/SNF complex to the PPARY2 promoter during preadipocyte differentiation (Salma et al., 2004). Interestingly, TFIIH recruitment to the PPARY2 promoter is SWI/SNF-dependent, and TFIIH recruitment to the RARß2 promoter is ligand-dependent, in opposition to SRC1 and the Med complex which are associated permanently to this promoter, irrespective of its activation state [Figures 2 and 4, (Flajollet et al., 2006)]. We observed, by coimmunoprecipitation and ChIP assays, that RAR interacts with Brg1 in a ligand-dependent manner (data not shown). Taken together, these data therefore suggest that TFIIH recruitment to the RAR $\beta 2$ promoter may be dependent on the association of a fully functional SWI/SNF complex.

Alternatively, the lack of detectable binding of SRC1 to RXR [data not shown and (Mouchon et al., 1999)], the obligate RAR dimerization partner, and the ability of BAF60c1\&2 to bind RXR, leaves open the possibility of the formation of a BAF60c/RXR/RAR/SRC1 complex. RXR-bound BAF60c could in this conformation synergize with RAR, by stabilizing the interaction of RAR with other components of the SWI/SNF complex such as Brg1. This would be reminiscent of the transcriptional potentiation of GATA4regulated genes by BAF60c, which occurs through the stabilization of the interaction between transcriptional regulators and Brg1, allowing further cooperation between the SWI/SNF complex and HATs (Lickert et al., 
2004). A in-depth investigation of the kinetics of the recruitment of the SWI/SNF complex to the promoter of endogenous RA-regulated genes is clearly needed to distinguish between these two possibilities. These "receptor-centered" hypothesis do not exclude, however, a model by which the SWI/SNF complex would interact directly with hyperacetylated histones or DNA through bromodomains or DNA-binding motifs (Mohrmann et al., 2005). During the course of these study and of others (Lefebvre et al., 2002b;Martin et al., 2005;Flajollet et al., 2006), we noted that several coactivators, which interact in a ligand-dependent manner with RAR in-vitro, such as SRC1, Med1 and to a lesser extent BAF60c2, are constitutively bound to the RAR $\beta 2$ promoter in intact cells. While this observation has been confirmed by others (Pavri et al., 2005), the molecular basis for this constitutive interaction is still unknown but may involve a receptorindependent recruitment.

Our results thus reveal an important role of BAF60c1 and BAF60c2 polypeptides in RA-dependent transcriptional regulation. Because BAF60c1 and BAF60c2 are expressed in a tissue-specific manner (Debril et al., 2004), this may impact on the cell-specific activity of RARs. Interestingly, this property is known to be dependent on the AF1 region, whose function can be modulated through a TFIIH-dependent phosphorylation (Rochette-Egly et al., 1997;Keriel et al., 2002). Taken together, our data as well as those from others establish an important role for SWI/SNF complexes in RAR-regulated transcription. It will be important to determine whether these complexes act by facilitating the assembly of the preinitiation complex, and/or by favoring the very first steps of transcriptional elongation. 


\section{ACKNOWLEDGEMENTS}

We wish to thank Drs J. Auwerx, B. Belandia and Z. Nie for the gift of plasmids. We are grateful to Aurore Guédin for technical assistance. This work was supported by grants from INSERM, Région Nord-Pas-de-Calais, Ligue Nationale contre le Cancer and Comité du Nord de la Ligue Nationale contre le Cancer. 


\section{BIBLIOGRAPHY}

Battaglioli,E., Andres,M.E., Rose,D.W., Chenoweth,J.G., Rosenfeld,M.G., Anderson,M.E., and Mandel,G. (2002). REST repression of neuronal genes requires components of the hSWI.SNF complex. J Biol Chem., $277,41038-41045$.

Belandia,B., Orford,R.L., Hurst,H.C., and Parker,M.G. (2002). Targeting of SWI/SNF chromatin remodelling complexes to estrogen-responsive genes. EMBO J., 21, 4094-4103.

Bourachot,B., Yaniv,M., and Muchardt,C. (2003). Growth inhibition by the mammalian SWI-SNF subunit Brm is regulated by acetylation. EMBO J, 22, 6505-6515.

Brand,C., Segard,P., Plouvier,P., Formstecher,P., Danze,P.M., and Lefebvre,P. (2002). Selective alteration of gene expression in response to natural and synthetic retinoids. BMC. Pharmacol., 2, 13.

Bultman,S., Gebuhr,T., Yee,D., La Mantia,C., Nicholson,J., Gilliam,A., Randazzo,F., Metzger,D., Chambon,P., Crabtree,G., and Magnuson,T. (2000). A Brg1 null mutation in the mouse reveals functional differences among mammalian SWI/SNF complexes. Mol. Cell, 6, 1287-1295.

Chiba,H., Muramatsu,M., Nomoto,A., and Kato,H. (1994). Two human homologues of Saccharomyces cerevisiae SWI2/SNF2 and Drosophila brahma are transcriptional coactivators cooperating with the estrogen receptor and the retinoic acid receptor. Nucl. Acid Res., 22, 1815-1820.

de Thé,H., Vivanco-Ruiz,M.M., Tiollais,P., Stunnenberg,H.G., and Dejean,A. (1990). Identification of a retinoic acid responsive element in the retinoic acid receptor beta gene. Nature, 343, 177-180.

De La Sema, ,I.L., Ohkawa,Y., and Imbalzano,A.N. (2006). Chromatin remodelling in mammalian differentiation: lessons from ATP-dependent remodellers. Nat. Rev. Genet., 7, 461-473.

Debril,M.B., Gelman,L., Fayard,E., Annicotte,J.S., Rocchi,S., and Auwerx,J. (2004). Transcription Factors and Nuclear Receptors Interact with the SWI/SNF Complex through the BAF60c Subunit. J. Biol. Chem., $279,16677-16686$.

Deckert,J. and Struhl,K. (2002). Targeted Recruitment of Rpd3 Histone Deacetylase Represses Transcription by Inhibiting Recruitment of Swi/Snf, SAGA, and TATA Binding Protein. Mol. Cell. Biol., 22, 6458-6470.

Depoix,C., Delmotte,M.H., Formstecher,P., and Lefebvre,P. (2001). Control of retinoic acid receptor heterodimerization by ligand-induced structural transitions. a novel mechanism of action for retinoid antagonists. J. Biol. Chem., 276, 9452-9459. 
Dilworth,F.J., Fromental-Ramain,C., Yamamoto,K., and Chambon,P. (2000). ATP-driven chromatin remodeling activity and histone acetyltransferases act sequentially during transactivation by RAR/RXR in vitro. Mol Cell, 6, 1049-1058.

Eberharter,A. and Becker,P.B. (2004). ATP-dependent nucleosome remodelling: factors and functions. J Cell Sci., 117, 3707-3711.

Flajollet,S., Lefebvre,B., Rachez,C., and Lefebvre,P. (2006). Distinct roles of the steroid receptor coactivator 1 and of Med1 in retinoid-induced transcription and cellular differentiation. J. Biol. Chem., 281, 20338-20348.

Fryer,C.J. and Archer,T.K. (1998). Chromatin remodelling by the glucocorticoid receptor requires the BRG1 complex. Nature, 393, 88-91.

Geffroy,N., Guédin,A., Dacquet,C. and Lefebvre, P. (2005) Cell cycle regulation of breast cancer cells through estrogen-induced activities of ERK and PI3 protein kinases. Mol. Cell. Endocrino., 237:11-23.

Hsiao,P.W., Fryer,C.J., Trotter,K.W., Wang,W., and Archer,T.K. (2003). BAF60a Mediates critical interactions between nuclear receptors and the BRG1 chromatin-remodeling complex for transactivation. Mol. Cell. Biol., 23, 6210-6220.

Ichinose,H., Garnier,J.M., Chambon,P., and Losson,R. (1997). Ligand-dependent interaction between the estrogen receptor and the human homologues of SWI2/SNF2. Gene, 188, 95-100.

Kemper,J.K., Kim,H., Miao,J., Bhalla,S., and Bae,Y. (2004). Role of an mSin3A-Swi/Snf chromatin remodeling complex in the feedback repression of bile acid biosynthesis by SHP. Mol. Cell. Biol., 24, 77077719.

Keriel,A., Stary,A., Sarasin,A., RochetteEgly,C., and Egly,J.M. (2002). XPD mutations prevent TFIIHdependent transactivation by nuclear receptors and phosphorylation of RAR alpha. Cell, 109, 125-135.

Kingston,R.E. and Narlikar,G.J. (1999). ATP-dependent remodeling and acetylation as regulators of chromatin fluidity. Genes Dev., 13, 2339-2352.

Lefebvre,B., Brand,C., Flajollet,S., and Lefebvre,P. (2006). Down-regulation of the tumor suppressor gene RARß2 through the PI3K/Akt signaling pathway. Mol Endocrinol., 20: 2109-2121.

Lefebvre,B., Brand,C., Lefebvre,P., and Ozato,K. (2002a). Chromosomal integration of retinoic acid response elements prevents cooperative transcriptional activation by retinoic acid receptor and retinoid $X$ receptor. Mol. Cell Biol., 22, 1446-1459. 
Lefebvre, B., Mouchon, A., Formstecher, P., and Lefebvre, P. (1998a) Distinct modes of interaction of the retinoic acid receptor alpha with natural and synthetic retinoids. Mol.Cell Endocrinol. 139, 161-169.

Lefebvre, B., Mouchon, A., Formstecher, P., and Lefebvre, P. (1998b) H11-H12 Loop Retinoic Acid Receptor Mutants Exhibit Distinct trans-Activating and trans-Repressing Activities in the Presence of Natural or Synthetic Retinoids. Biochemistry 37[26], 9240-9249.

Lefebvre,B., Ozato,K., and Lefebvre,P. (2002b). Phosphorylation of histone H3 is functionally linked to retinoic acid receptor $\beta$ promoter activation. EMBO Rep., 3, 340-348.

Lefebvre,P., Martin,P.J., Flajollet,S., Dedieu,S., Billaut,X., and Lefebvre,B. (2005). Transcriptional activities of retinoic acid receptors. Vitam. Horm., 70, 199-264.

Lemon,B., Inouye,C., King,D.S., and Tjian,R. (2001). Selectivity of chromatin-remodelling cofactors for ligand-activated transcription. Nature, 414, 924-928.

Lickert,H., Takeuchi,J.K., Von,B., I, Walls,J.R., McAuliffe,F., Adamson,S.L., Henkelman,R.M., Wrana,J.L., Rossant,J., and Bruneau,B.G. (2004). Baf60c is essential for function of BAF chromatin remodelling complexes in heart development. Nature, 432, 107-112.

Link,K.A., Burd,C.J., Williams,E., Marshall,T., Rosson,G., Henry,E., Weissman,B., and Knudsen,K.E. (2005). BAF57 Governs Androgen Receptor Action and Androgen-Dependent Proliferation through SWI/SNF. Mol. Cell. Biol., 25, 2200-2215.

Martin,P.J., Delmotte,M.H., Formstecher,P., and Lefebvre,P. (2003). PLZF is a negative regulator of retinoic acid receptor transcriptional activity. Nucl. Recept., 1, 6.

Martin,P.J., Lardeux,V., and Lefebvre,P. (2005). The proliferating cell nuclear antigen regulates retinoic acid receptor transcriptional activity through direct protein-protein interaction. Nucl. Acids. Res., 33, 4311-4321.

Mohrmann,L. and Verrijzer,C.P. (2005). Composition and functional specificity of SWI2/SNF2 class chromatin remodeling complexes. Biochim. Biophys. Acta, 1681, 59-73.

Mouchon,A., Delmotte,M.-H., Formstecher,P., and Lefebvre,P. (1999). Allosteric Regulation of the discriminative responsiveness of retinoic acid receptor to natural and synthetic ligands by retinoid $X$ receptor And DNA. Mol. Cell. Biol., 19, 3073-3085.

Murphy,D.J., Hardy,S., and Engel,D.A. (1999). Human SWI-SNF Component BRG1 Represses Transcription of the c-fos Gene. Mol. Cell. Biol., 19, 2724-2733.

Olave,I., Wang,W., Xue,Y., Kuo,A., and Crabtree,G.R. (2002a). Identification of a polymorphic, neuron- 
specific chromatin remodeling complex. Genes Dev., 16, 2509-2517.

Olave,I.A., Reck-Peterson,S.L., and Crabtree,G.R. (2002b). Nuclear actin and actin-related proteins in chromatin remodeling. Annu. Rev. Biochem., 71, 755-781.

Pavri,R., Lewis,B., Kim,T.K., Dilworth,F.J., Erdjument-Bromage,H., Tempst,P., De Murcia,G., Evans,R., Chambon,P., and Reinberg,D. (2005). PARP-1 determines specificity in a retinoid signaling pathway via direct modulation of mediator. Mol Cell, 18, 83-96.

Peterson,C.L. (2002). Chromatin remodeling: nucleosomes bulging at the seams. Curr. Biol., 12, R245R247.

Phelan,M.L., Sif,S., Narlikar,G.J., and Kingston,R.E. (1999). Reconstitution of a core chromatin remodeling complex from SWI/SNF subunits. Mol. Cell, 3, 247-253.

Prima,V., Depoix,C., Masselot, B., P. Formstecher and Lefebvre P. (2000) Alteration of the glucocorticoid receptor subcellular localization by non steroidal compounds. J. Ster. Biochem. Mol. Biol., 72:1-12.

Roberts,C.W. and Orkin,S.H. (2004). The SWI/SNF complex--chromatin and cancer. Nat. Rev. Cancer, 4, $133-142$

RochetteEgly,C., Adam,S., Rossignol,M., Egly,J.M., and Chambon,P. (1997). Stimulation of RAR alpha activation function AF-1 through binding to the general transcription factor TFIIH and phosphorylation by CDK7. Cell, 90, 97-107.

Salma,N., Xiao,H., Mueller,E., and Imbalzano,A.N. (2004). Temporal recruitment of transcription factors and SWI/SNF chromatin-remodeling enzymes during adipogenic induction of the peroxisome proliferatoractivated receptor y nuclear hormone receptor. Mol. Cell. Biol., 24, 4651-4663.

Sif,S., Saurin,A.J., Imbalzano,A.N., and Kingston,R.E. (2001). Purification and characterization of mSin3Acontaining Brg1 and hBrm chromatin remodeling complexes. Genes Dev., 15, 603-618.

Simone,C., Forcales,S.V., Hill,D.A., Imbalzano,A.N., Latella,L., and Puri,P.L. (2004). p38 pathway targets SWI-SNF chromatin-remodeling complex to muscle-specific loci. Nat. Genet., 36, 738-743.

Trotter,K.W. and Archer,T.K. (2004). Reconstitution of Glucocorticoid receptor-dependent transcription in vivo. Mol. Cell. Biol., 24, 3347-3358.

Underhill,C., Qutob,M.S., Yee,S.P., and Torchia,J. (2000). A novel nuclear receptor corepressor complex, $\mathrm{N}-\mathrm{CoR}$, contains components of the mammalian SWI/SNF complex and the corepressor KAP-1. J. Biol. Chem., 275, 40463-40470. 
Wang,W. (2003). The SWI/SNF family of ATP-dependent chromatin remodelers: similar mechanisms for diverse functions. Curr. Top. Microbiol. Immunol, 274, 143-169.

Wang,W., Xue,Y., Zhou,S., Kuo,A., Cairns,B.R., and Crabtree,G.R. (1996). Diversity and specialization of mammalian SWI- SNF complexes. Genes Dev., 10, 2117-2130.

Wang,Z., Zhai,W., Richardson,J.A., Olson,E.N., Meneses,J.J., Firpo,M.T., Kang,C., Skarnes,W.C., and Tjian,R. (2004). Polybromo protein BAF180 functions in mammalian cardiac chamber maturation. Genes Dev., 18, 3106-3116.

Yan,Z., Cui,K., Murray,D.M., Ling,C., Xue,Y., Gerstein,A., Parsons,R., Zhao,K., and Wang,W. (2005). PBAF chromatin-remodeling complex requires a novel specificity subunit, BAF200, to regulate expression of selective interferon-responsive genes. Genes Dev., 19, 1662-1667. 


\section{FIGURES LEGENDS}

Figure 1. BAF60c proteins possess RAR-coactivating properties in HeLa and P19 cells. A) BAF60c1 and BAF60c2 overexpression potentiate RA-induced transcription. HeLa cells were transfected with the DR5-tk Luc reporter gene (NT), with this reporter gene and expression vectors coding for RAR $\alpha$ and RXR $\alpha$ (Control), or with the DR5-tk Luc reporter, RAR $\alpha$ and RXR $\alpha$ expression vectors and an expression vector coding for the indicated protein. Twenty four hours after transfection, cells were challenged or not with 100nM atRA for 16 hours. Renilla and firefly luciferase activities were assayed and expressed as a fold induction over the basal level of control cells, which was arbitrarily set to 1. B) Coactivating properties of $\mathrm{SRC1}$, BAF57, BAF250 and BAF60c2 on ER $\alpha$ transcriptional activities. HeLa cells were transfected as in A) using an $E R E_{3 .}$ tk Luc reporter gene and a pCMV-ER $\alpha$ expression vector. C) Coactivating properties of SRC1, BAF57, BAF250 and BAF60c2 on GR transcriptional activities. HeLa cells were transfected as in A) using an $\mathrm{GRE}_{3 .}$.tk Luc reporter gene and a pRSV-GR expression vector. D) Knockdown of the expression of BAF60c1\&2 affects the transcriptional response of the RARß2 promoter to atRA. P19 cells were transfected either with a plasmid encoding for an antiBAF60c1\&2 shRNA (BAF60c1\&2 RNAi) or an expression vector coding for BAF60c2. The level of expression of the BAF60c1\&2 mRNA was assayed by RT-PCR (upper panel). The level of expression of the RAR $\beta 2$ gene was assessed by RT-QPCR at different times and expressed as a fold induction over the basal level of untreated cells, set arbitrarily to 1.

Figure 2. BAF60c1\&2 interact with RARQ in intact cells. A) BAF60c proteins interact with RARQ in a ligand-independent manner. RAR $\alpha$ or BAF250 were immunoprecipitated from P19 whole cell extracts, and the association of BAF60c or RAR $\alpha$ with the RAR $\alpha$ or BAF250 precipitate was detected by western blot analysis. B) Colocalization of RAR $\alpha$ and BAF60c proteins. HeLa cells were transfected with an EGFPhRAR $\alpha$ expression vector and fixed with paraformaldehyde 24 hours after transfection. Endogenous BAF60c was detected by indirect immunofluorescence. C) BAF60c proteins bind to the RAR 32 promoter. The RAR $\beta 2$ promoter immunoprecipitated from formaldehyde-crosslinked chromatin by antibodies against RAR $\alpha$, SRC1 or BAF60c1\&2 was subjected to regular PCR (upper panel) or to Q-PCR (lower diagram) using RARB2 promoter-specific primers. Results are expressed relative to the PCR signal detected with $10 \%$ input DNA after substraction of the signal generated in control (no antibody, No Ab) immunoprecipitates $(n=3)$. D) RNA polymerase2, but not BAF60c1\&2, associates to exon 3 of the RARß2 gene. Immunoprecipitated DNA was amplified with primers specific for the RARß2 exon 3 region $(+165$ to +524$)$ and quantified as described in Flajollet et al., 2006 and above. 
Figure 3. BAF60c1 and BAF60c2 coactivate RARQ in a SRC1-dependent manner. A) SRC1 synergizes with BAF60c1\&2. HeLa cells were transfected with the DR5-tk Luc reporter gene and the indicated combination of expression vectors. The luciferase activity was assayed after challenging cells with vehicle (DMSO, - lanes) or 100nM atRA (+ lanes). Results are expressed as in Figure 1. B) Dosedependency of SRC1 synergy with BAF60c1 or BAF60c2. HeLa cells were transfected with the indicated combination of expression vectors and the DR5-tk Luc reporter gene, with increasing amount of SRC1 expression vector (50, 250 and $500 \mathrm{ng}$ ). Luciferase assays were assayed and are displayed as described in Figure 1. C) Down-regulation of SRC1 expression affects BAF60c2 coactivating capacity. HeLa cells were transfected with the DR5-tk Luc

Figure 4. BAF60c1\&2 do not interact physically with SRC1. A) In-vitro interaction of BAF proteins with SRC1. Radiolabeled SRC1 was incubated with GST or GST fusion proteins as indicated. The GST pulldown procedure is described in the Materials and Methods section. The lower panel shows a portion of the gel previously stained with Coomassie Blue to assess the quantity of GST fusion proteins used in the assay. B) Knockdown of SRC1 expression in P19 cells. P19 cells stably expressing an anti-SRC1 shRNA were isolated and characterized (Flajollet et al., 2006). The level of expression of SRC1 in wt P19 and shRNA-expressing cells (SRC1 RNAi) was assessed by western blot analysis of P19 whole cell extract (50 $\mu \mathrm{g}$ proteins/lane). C) Knockdown of SRC1 expression does not prevent BAF60c1\&2 tethering to the RARß2 promoter. Chromatin immunoprecipitation with antiSRC1 or antiBAF60c antibodies were carried out as described in Figure 2. Results are expressed relative to the PCR signal detected with $10 \%$ input DNA.

Figure 5. Molecular interactions of SWISNF subunits. A) Interaction of ER $\alpha, R A R \alpha, R A R \beta, R A R Y$ and RXR $\alpha$ with BAF proteins. ${ }^{35} \mathrm{~S}$-labeled nuclear receptors were synthesized in-vitro, and GST pulldowns were performed as described in the Materials and Methods section. Ligand concentrations were 100nM for each condition. B) and C) Mapping RAR $\alpha$ domains interacting with BAF60c1 and BAF60c2. RAR $\alpha$ or its derivatives were ${ }^{35}$ S-labeled and tested for their interaction with BAF60c2 (B) or BAF60c1 and BAF60c2 (C). Left panels show a diagram of RAR $\alpha$ and of the mutants used in GST pulldown experiments. 


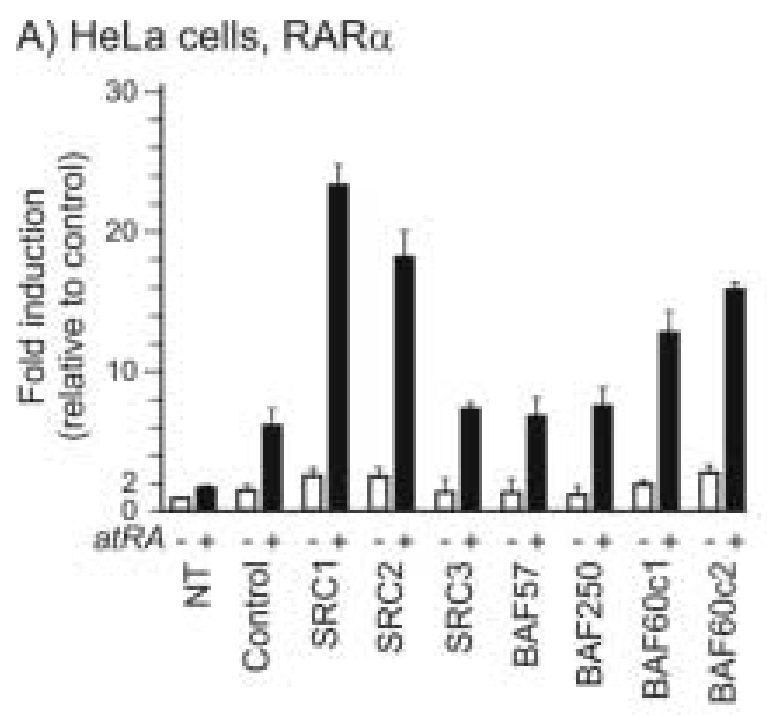

B) HeLa cells, ER $\alpha$

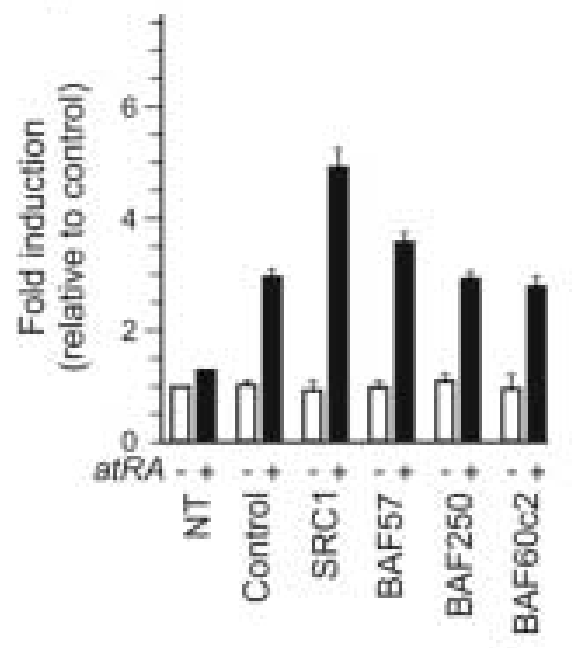

C) HeLa cells, GR

D) P19 cells
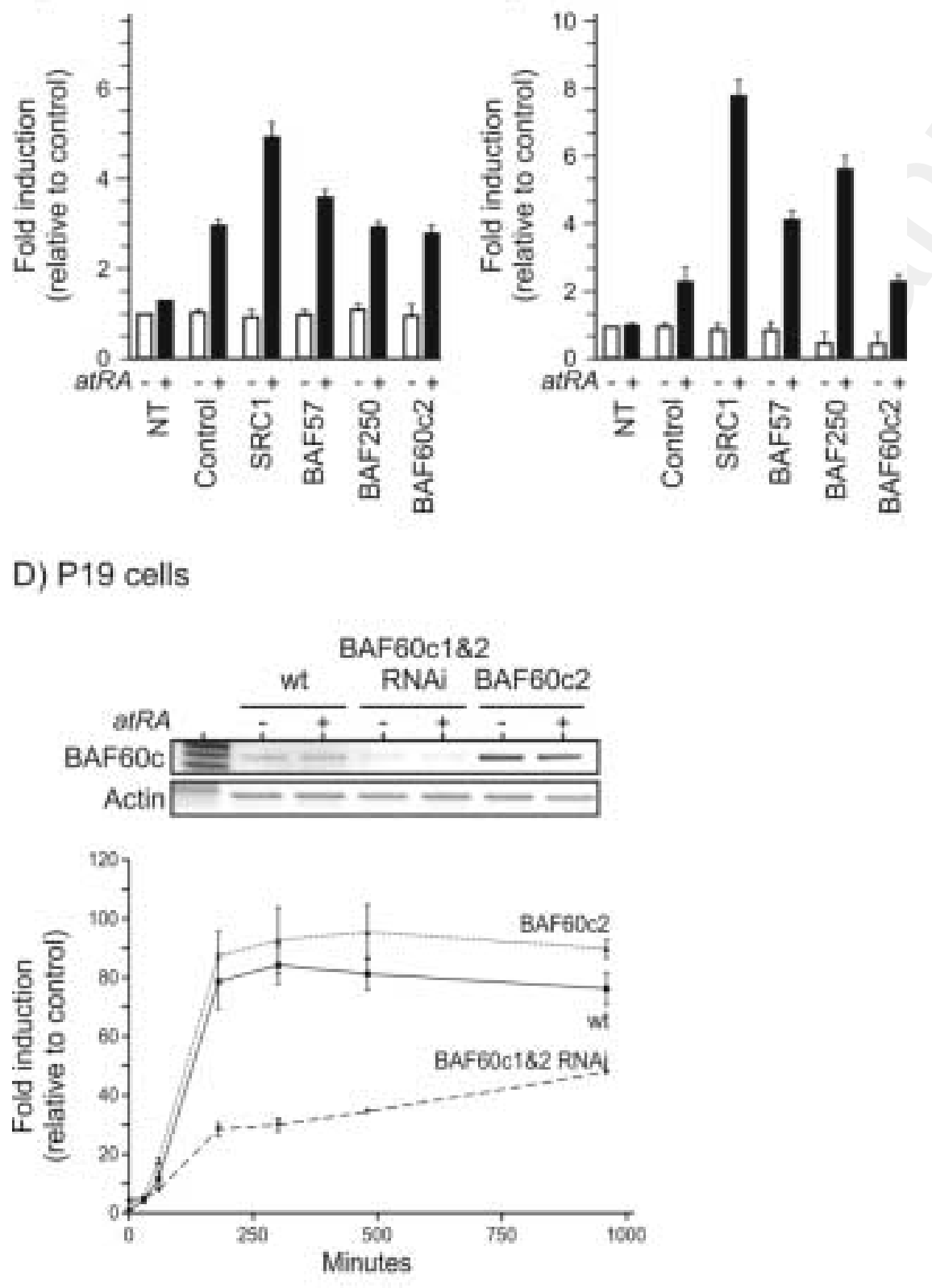

Figure 1; Flajollet et al 
A)

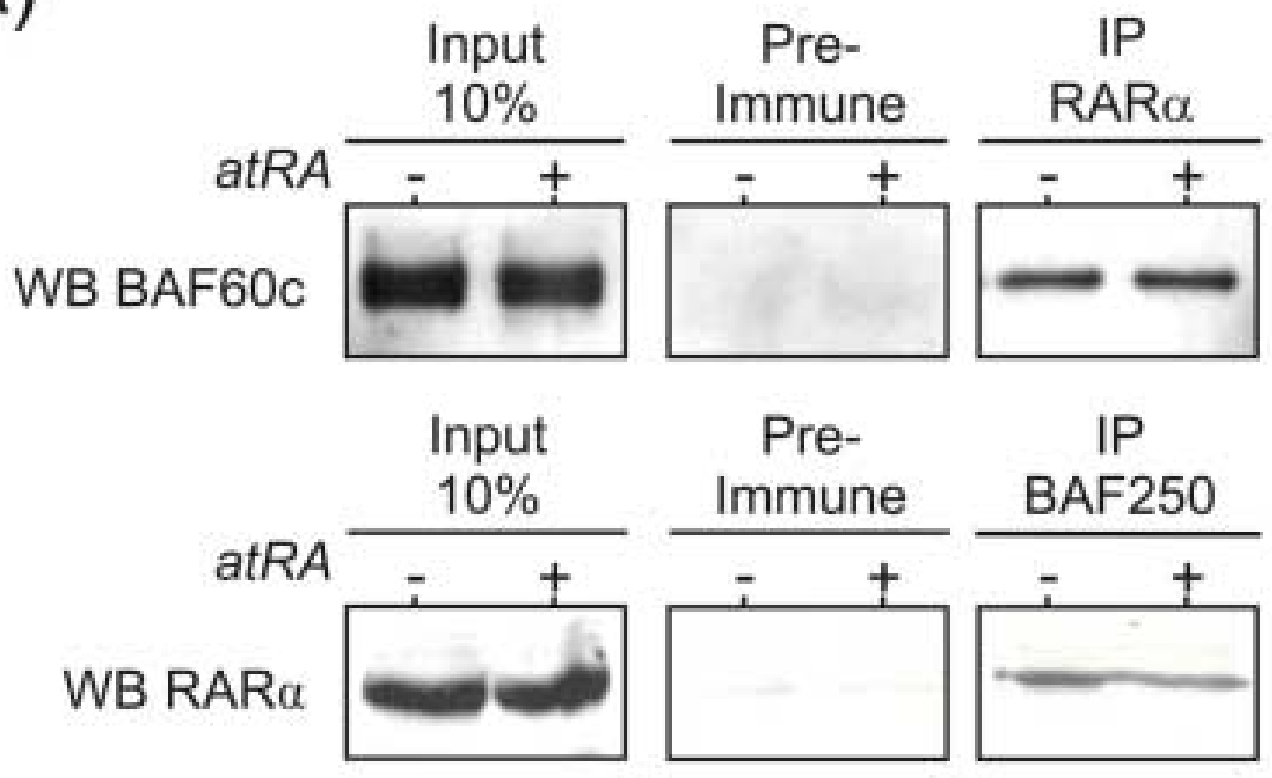

B)

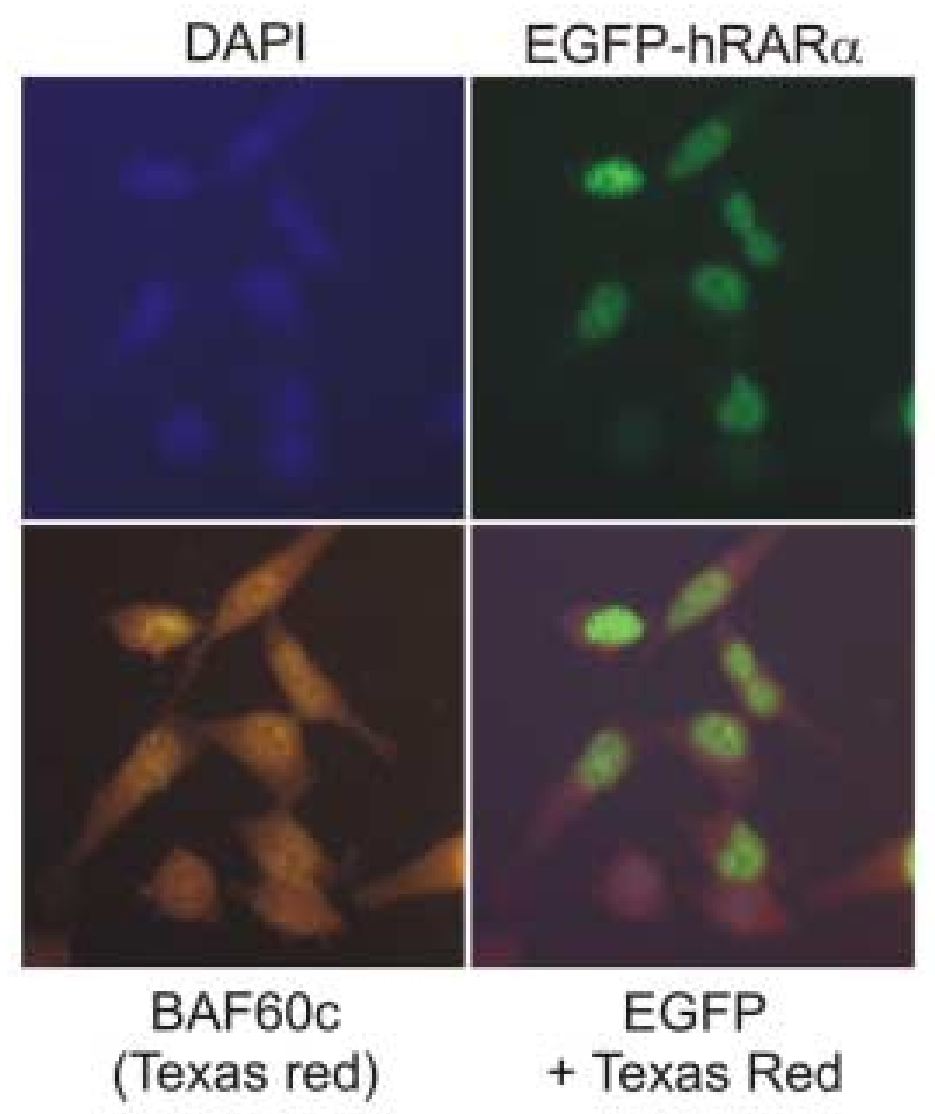

Figure 2; Flajollet et al, left panel 
C)

\begin{tabular}{|c|c|c|c|c|}
\hline $\begin{array}{l}10 \% \\
\text { Input }\end{array}$ & No $A b$ & RAR $\alpha$ & SRC1 & $\begin{array}{c}\text { BAF } 60 \mathrm{c} \\
1 \& 2 \\
\end{array}$ \\
\hline$=+$ & $=+$ & $=+$ & -7 & -1 \\
\hline-- & & - & - & \\
\hline
\end{tabular}

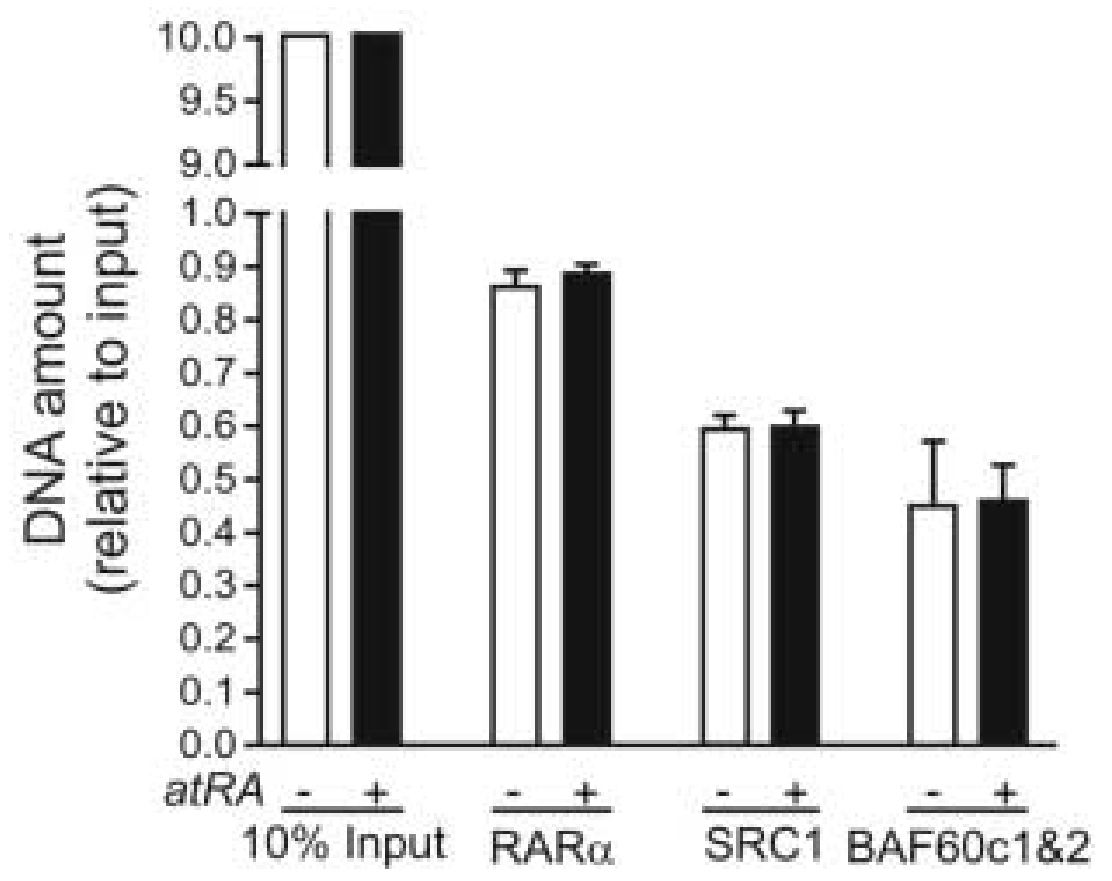

D)

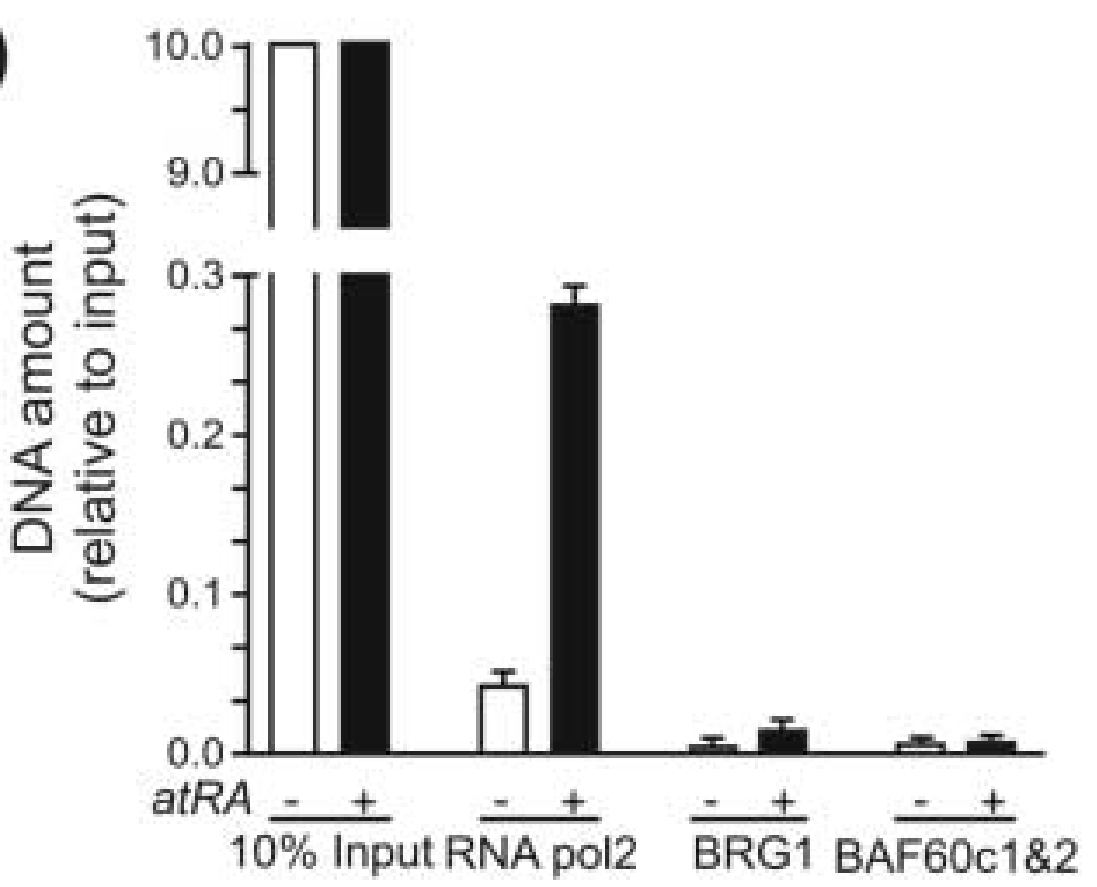

Figure 2; Flajollet et al, right panel 
A)

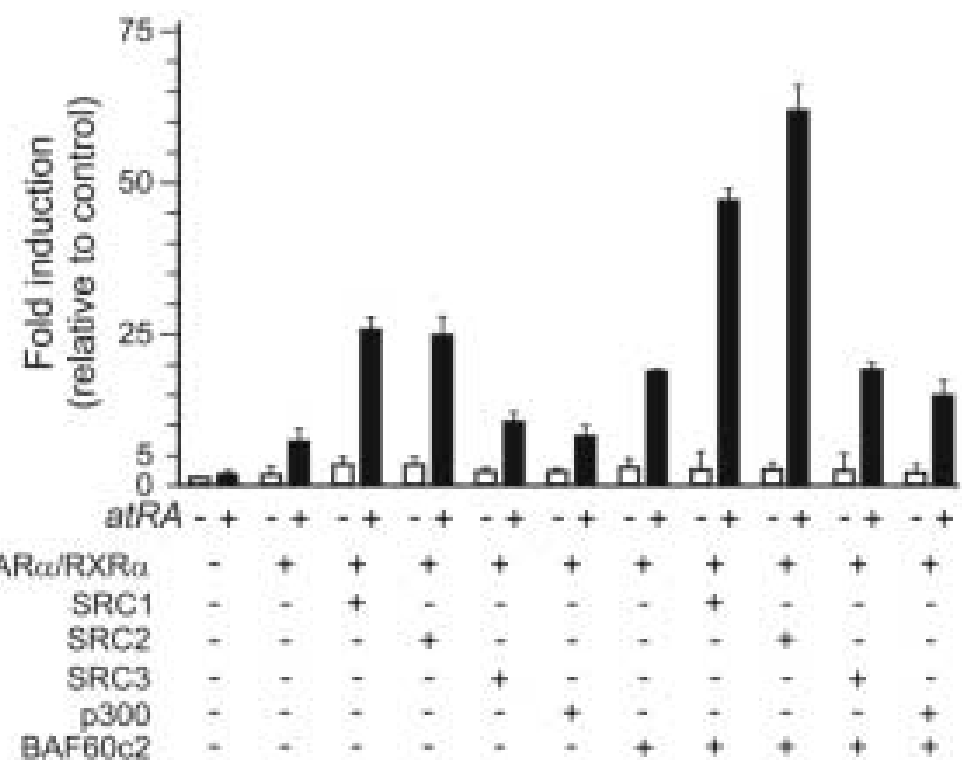

B)

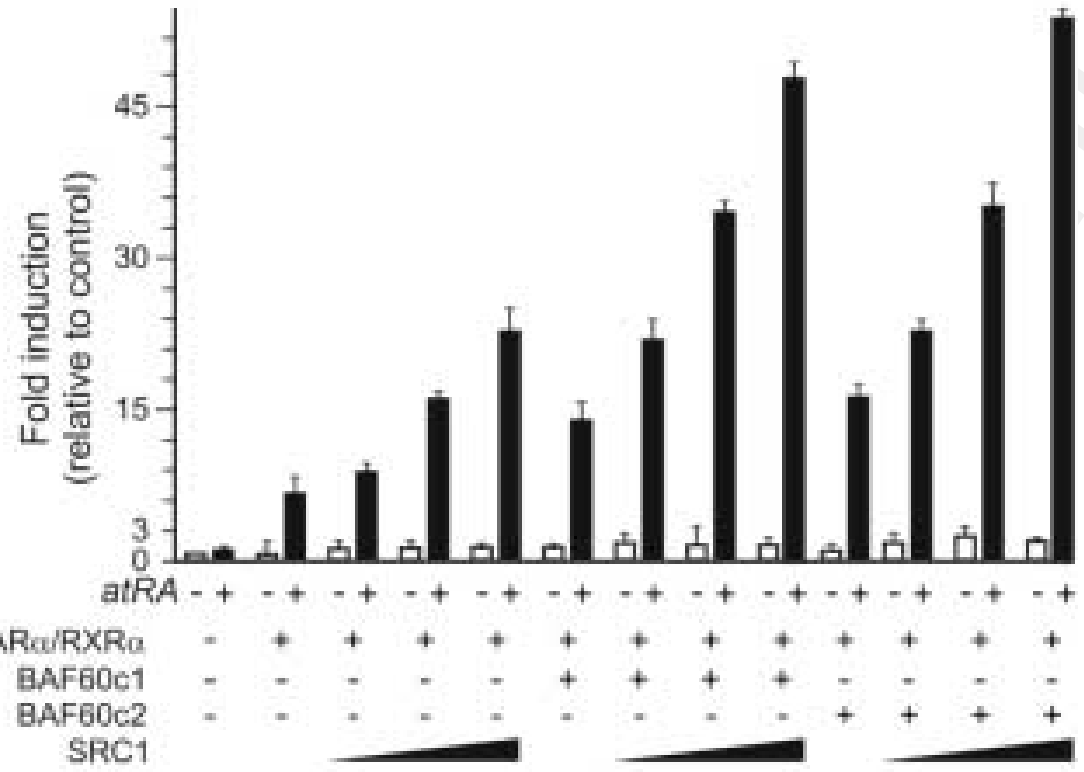

C)

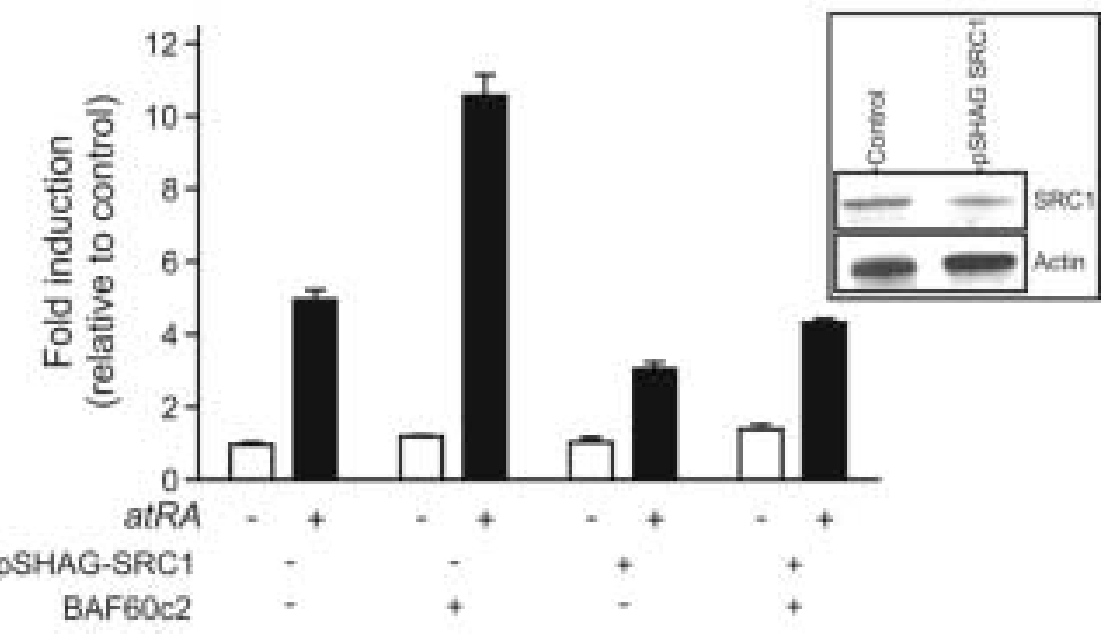

Figure 3; Flajollet et al 
A)

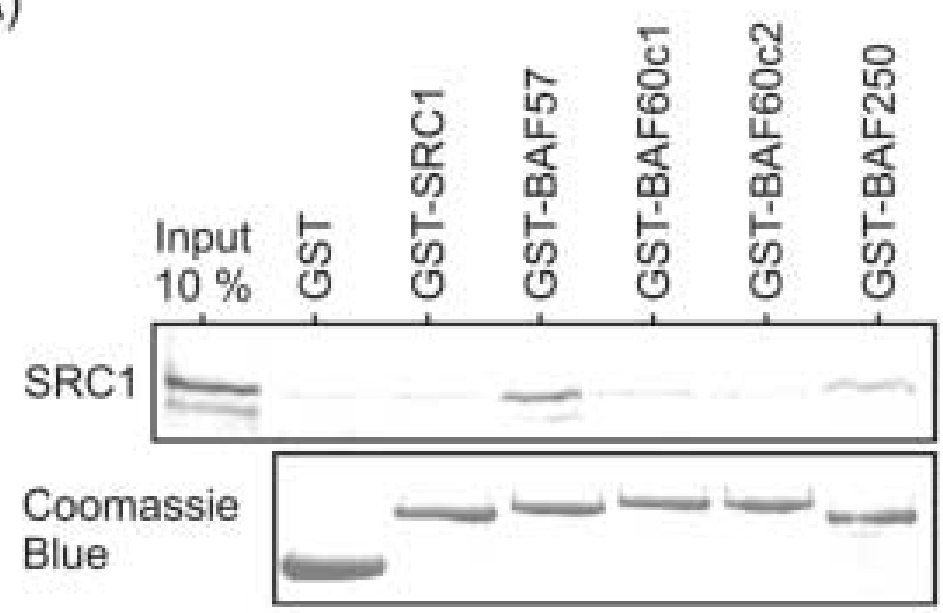

B)

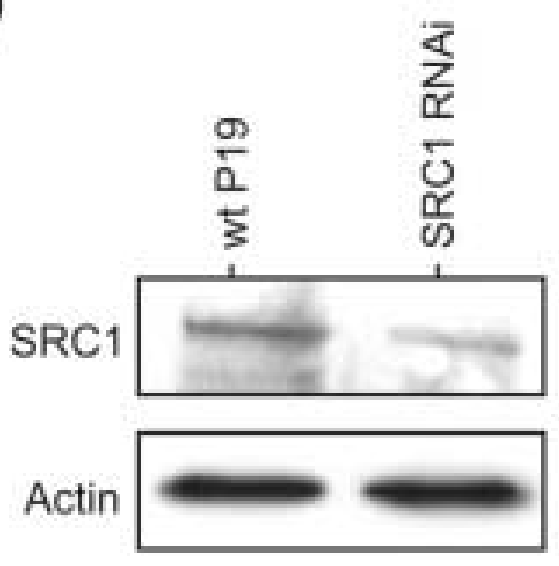

C)

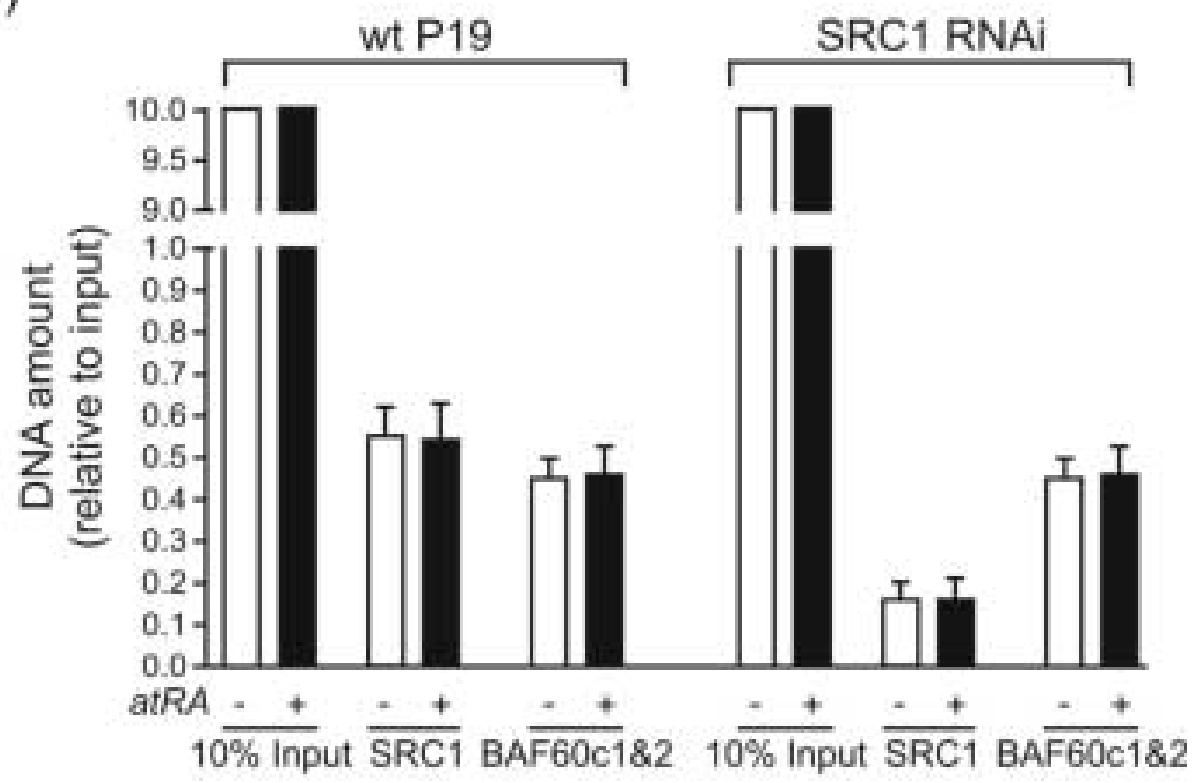

Figure 4; Flajollet et al 
A)
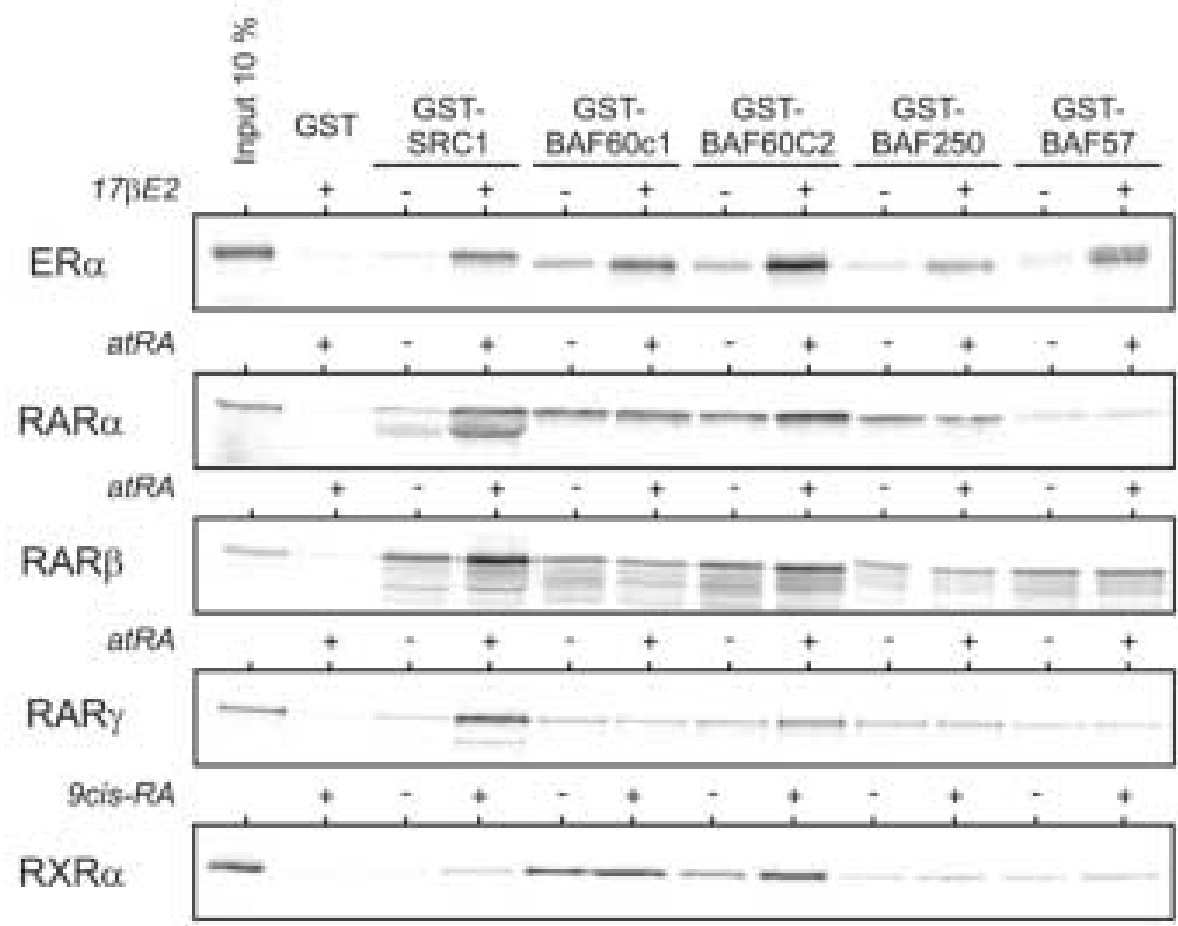

B)
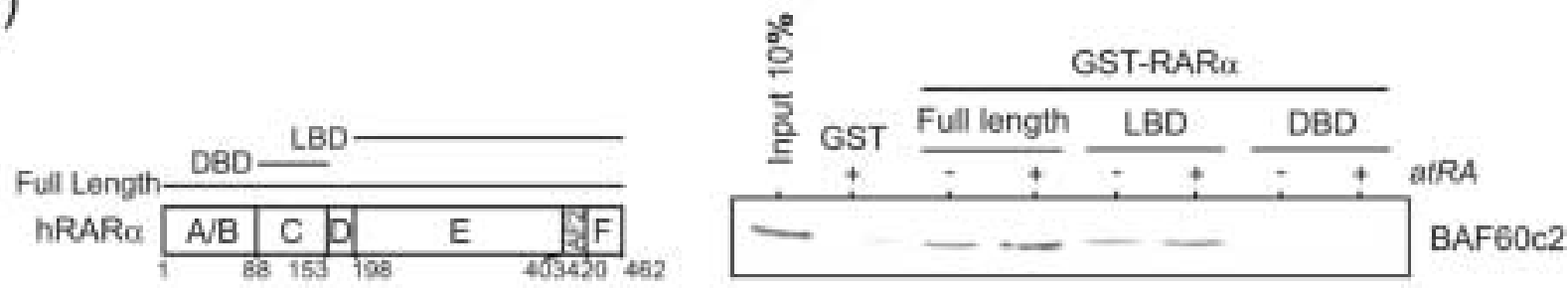

C)
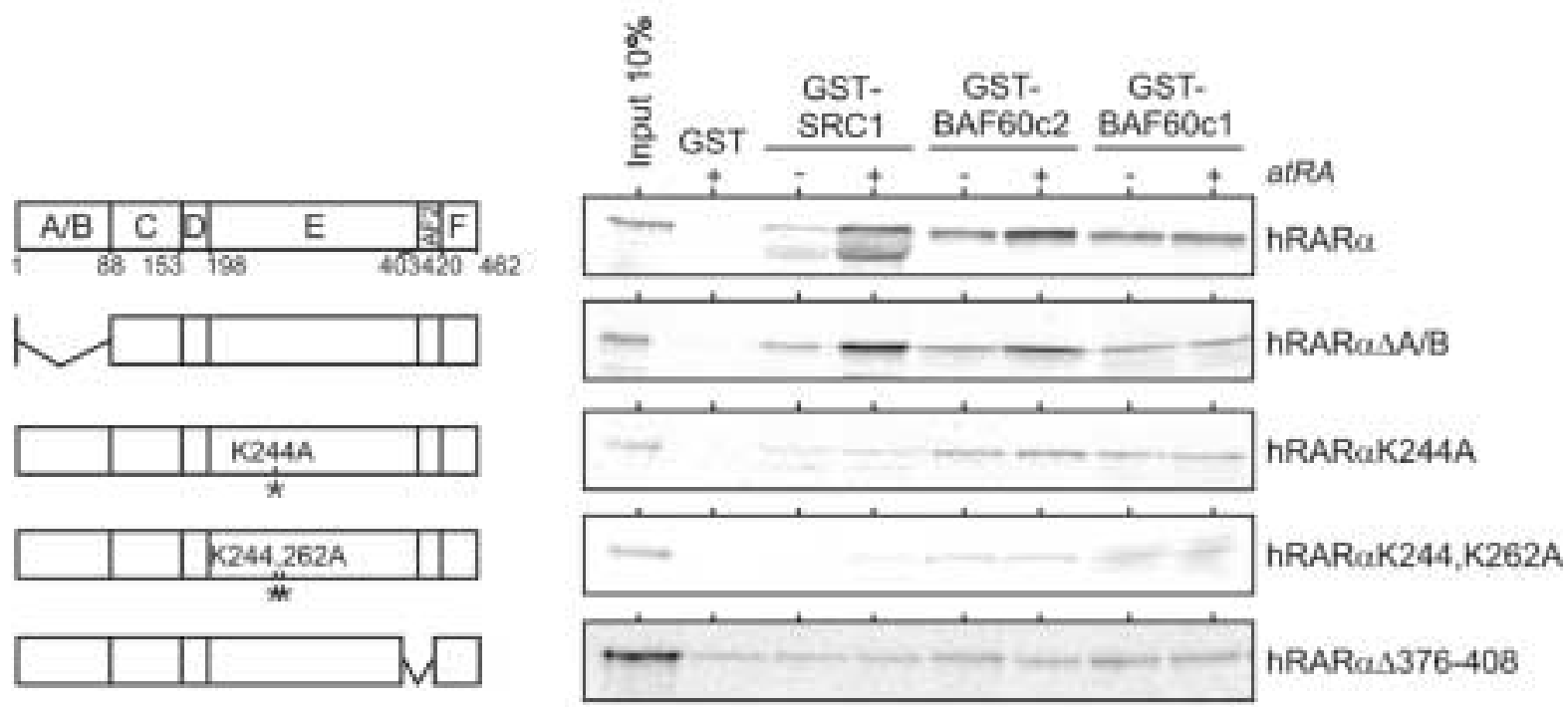